МЕТАЛДАРДЫН Сd(II), Нg(II), In(III), TI(III), Sn(II) И Рb(II) КҮКІРТТІ ОРГАНИКАЛЫҚ ЛИГАНДТЫ КЕШЕНДІ КОСЫЛЫСТАРЫНЫН КЕНІСТІКТІК ҚҰРЫЛЫСТАРЫНЫН ЕРЕКШЕЛІКТЕРІ

Е.Н. Иващенко, Р.А. Омарова, Х.К. Оспанов

Құрамында күкіртті органикалық лиганда бар металдардың кешенді қосылыстарының геометриялық параметрлері есептелдi.

Металл - күкірт байланыс ұзындывы $\mathrm{Hg}(\mathrm{II})$-пен кешенді құосылысында ең үлкені болса, кімісі Tl (III)- мен қзосылысында болады.

\title{
THE PECULIARITIES OF THE SPATIAL STRUCTURE OF Cd(II), Hg(II), In(III), TI(III), Sn(II) AND Pb(II) METALLIC SALTS COMPLEX COMPOUNDS
}

\author{
E.N. Ivashchenko. R.A. Omarova. Kh.K. Ospanov
}

The geometrical parameters of complex compounds of Cd (II), Hg (II), In (III), Tl (III), Sn (II), Pb(II) metal salts with sulpher containing organic ligand were carried out using the MOPAC - 7.0 program by the guantum chemical PM3 method.

It has been shown that the shortest $M-S$ connection between a complex forming ion and a sulpher containing ligand forms in $\mathrm{Hg}$ (II) complexes, and the longest connection forms in Tl (III) complexes.

УДК 556.114

\section{ИССЛЕДОВАНИЕ ГИДРОГЕЛЕВЫХ КОМПОЗИТОВ НА ОСНОВЕ АМОРФНЫХ ФОСФАТОВ И СОПОЛИМЕРОВ АКРИЛАМИДА ИК-СПЕКТРОСКОПИЕЙ}

\author{
К.И. Иманбеков, Р.Г. Рыскалиева, К.М. Тамтиева, Г.И. Курбанова \\ Казахский национальный университет им. аль-Фараби \\ АО «Институт химических наук им. А.Б. Бектурова », г. Алматы
}

\begin{abstract}
Рассмотрены изменения в колебательных спектрах нано-аморфных фосфатов, образующихся в порах полиакриламидных гидрогелей при синтезе композитных материалов. Показано, что аморфные фазы ортофосфатов кальция, кальция - магния, инкорпорированные в гидрогелевую структуру, имеют микропористую структуру.

Одним из направлений развития медико-биологического материаловедения является разработка методов синтеза и получения биосовместимых композитных материалов на основе гидроксиапатита (ГА), а также полимерных нанобиокомпозитов, содержащих в составе ГА и другие ортофосфаты кальция, в частности, аморфные монофосфаты кальция-магния, моно-дифосфаты кальция и моно-дифосфаты кальция-магния [1]. Свойства аморфных фосфатов приведены в табл. 1.
\end{abstract}

Таблица 1

Состав исходных аморфных фосфатов [1].

\begin{tabular}{|c|c|c|c|c|c|}
\hline $\begin{array}{l}\text { № } \\
\Pi / \Pi\end{array}$ & $\begin{array}{c}\text { Наименование вещества, } \\
\text { условная формула }\end{array}$ & $\begin{array}{c}\text { Молекулярный } \\
\text { вес }\end{array}$ & $\begin{array}{c}\text { Содержание } \\
\text { воды в АФК, } \\
\text { масс. } \%\end{array}$ & $\begin{array}{c}\text { Мольное } \\
\text { отношение } \\
\mathrm{H}_{2} \mathrm{O} / \text { фосфат }\end{array}$ & $\begin{array}{c}\text { Число } \\
\text { молекул } \\
\mathrm{H}_{2} \mathrm{O} \mathrm{на} \\
\text { ион }\end{array}$ \\
\hline 1 & $\begin{array}{c}\text { Моно-дифосфат кальция } \\
\mathrm{Ca}_{1}\left(\mathrm{PO}_{4}\right)_{0.42}\left(\mathrm{P}_{2} \mathrm{O}_{7}\right)_{0.18}\end{array}$ & 111.22 & 80.2 & 25.0 & 15.6 \\
\hline 2 & $\begin{array}{c}\text { Монофосфат кальция-магния } \\
\mathrm{Ca}_{1} \mathrm{Mg}_{0.43}\left(\mathrm{PO}_{4}\right)_{0.95}\end{array}$ & 140.57 & 80.5 & 32.2 & 13.5 \\
\hline 3 & $\begin{array}{l}\text { Моно-дифосфат кальция- } \\
\text { магния } \\
\mathrm{Ca}_{1} \mathrm{Mg}_{0.11}\left(\mathrm{PO}_{4}\right)_{0.65}\left(\mathrm{P}_{2} \mathrm{O}_{7}\right)_{0.07}\end{array}$ & 116.57 & 80.1 & 26.1 & 14.2 \\
\hline
\end{tabular}


В качестве полимерной пространственно-сшитой матрицы используются в основном гидрогели, синтезированные трехмерной сополимеризацией мономеров акрилового ряда. Нанопоры, образующиеся при определенных условиях синтеза, могут использоваться в качестве нанореакторов.

В настоящей статье нами проведено исследование методами ИК- и КР спектроскопии наноструктурированных полимерных гидрогелей на основе слабосшитого акриламида, а также включающих образованные внутри гелевого пространства АФСа и АФСа-Мg, с целью определения промежуточных состояний, диагностики кристалличности и неоднородности состава в процесса синтеза.

\section{Материалы и методики исследования}

Синтез исходных фосфатов аморфной природы осуществлялся по методике, описанной в работе [2].

Гелеобразование проводилось в водной среде при комнатной температуре с применением окислительно-восстановительной системы. Общее количество трехмерно-сшитого акриламидного сополимера в гидро-гелях варьировалось в пределах 5-50\%. Содержание сшивающего агента (N,N'бисметакриламид) варьировалось от 0,01 до $1 \%$. Гидрогелевые сополимеры, синтезированные в зависимости от времени и условий обработки матрицы, обладают высокой биосовместимостью [3]. Полная методика получения полиакриламидного гидрогеля приведена в работе [4].

Формирование наноструктурных АФСа и АФСа-Mg в поровом пространстве гидрогелевой матрицы с превалирующим размером 40-100 нм проводили путем последовательной ее обработки водными растворами $\left(\mathrm{NH}_{4}\right)_{2} \mathrm{HPO}_{4}, \mathrm{Ca}\left(\mathrm{NO}_{3}\right)_{2}$ и $\mathrm{NH}_{4} \mathrm{OH}$ при $\mathrm{pH} 8-10$. Нами были установлены оптимальные соотношения реагентов, температуры и времени обработки гидрогеля, позволяющие достичь образованию наноаморфных фосфатов Са и $\mathrm{Ca}-\mathrm{Mg}$ в порах полиакриламидного сополимера.

Инфракрасные спектры записывались на спектрометре FT-IR Nicollet 5700 по методике нарушенного полного внутреннего отражения на монокристалле $\mathrm{Zn}-\mathrm{Se}$ при разрешении $4 \mathrm{~cm}^{-1}$, точности измерений $\pm 0,5 \mathrm{~cm}^{-1}$. Рамановские спектры записывались на спектрометре «FT-Raman Module» с использованием поляризованного излучения Не- $\mathrm{Ne}$ лазера с длиной волны 780 нм и мощностью $0,3 \mathrm{~W}$. Кислотный показатель использованных в исследовании растворов и суспензий контролировался с помощью иономера марки Mettler Toledo.

\section{Результаты исследований и их обсуждение}

ИК-спектроскопические исследования подтверждают результаты рентгенофазового анализа. В таблице приведены волновые числа максимумов полос поглощения в ИК-спектре твердых веществ, согласно $[1,2,5]$.

Данные табл. 2 показывают, что самая широкая и интенсивная из спектральных полос, лежащая выше 2700-2800 $\mathrm{cm}^{-1}$, отвечает валентным симметричным и асимметричным колебаниям химических связей $\mathrm{O}-\mathrm{H}$ в молекулах $\mathrm{H}_{2} \mathrm{O}(\mathrm{vOH})$. Следующая по величине линия с максимумом около 1636-1638 $\mathrm{cm}^{-1}$ соответствует деформационным колебаниям связей $\mathrm{O}-\mathrm{H}(\delta \mathrm{OH})$.

Таблица 2

Колебательные частоты $\left(\mathrm{cm}^{-1}\right)$ образцов гидрогеля (А) и композитных материалов на их основе (АБ) и (АВ)

\begin{tabular}{|c|c|c|c|c|c|}
\hline $\mathrm{AA}[$ ] & Л-2 [ ] & $\mathrm{A}$ & АБ & $\mathrm{AB}$ & отнесение \\
\hline 3340 & 3340 & 3400 & \multicolumn{2}{|c|}{$3355-3349$} & $v(\mathrm{OH})$ \\
\hline \multicolumn{6}{|l|}{3290} \\
\hline 3160 & 3189 & 3180 & $3175-3$ & & $v(\mathrm{OH}, \mathrm{NH})$ \\
\hline \multirow[t]{2}{*}{3000} & 2960 & & & & \\
\hline & 2925 & 2935 & & & $v(\mathrm{NH})$ \\
\hline \multirow[t]{3}{*}{2820} & & 2850 & & & $v(\mathrm{CH})$ \\
\hline & & & \multicolumn{2}{|c|}{2365} & \\
\hline & 2200 & 2200 & & & \\
\hline 1670 & 1660 & 1665 & \multicolumn{2}{|c|}{1660} & $v(\mathrm{C}=\mathrm{O})$ \\
\hline
\end{tabular}




\begin{tabular}{|c|c|c|l|l|c|c|}
\hline 1600 & 1600 & 1600 & & 1605 & $\delta(\mathrm{NH})$ \\
\hline 1430 & 1455 & 1450 & & 1440 & $\delta(\mathrm{OH})$ \\
\hline & 1415 & 1415 & & 1410 & $\delta(\mathrm{CH})$ \\
\hline 1350 & 1350 & 1350 & & 1355 & $\delta(\mathrm{C}-\mathrm{C})$ \\
\hline & 1315 & 1320 & & $1315-1320$ & $\delta(\mathrm{C}-\mathrm{N})$ \\
\hline & 1180 & 1180 & \multicolumn{3}{|l|}{} \\
\hline 1140 & 1120 & 1130 & & $1120-1125$ & $v^{\text {as }}(\mathrm{P}=\mathrm{O})$ \\
\hline 1050 & & & & & $1085_{\text {пл }}-1050_{\text {макс }}$ & $v^{\mathrm{s}}(\mathrm{P}-\mathrm{O})$ \\
\hline 984 & & & & & $962-960$ & $\mathrm{HPO}_{4}{ }^{2-}$ \\
\hline & & & & & 880 & $\gamma(\mathrm{P}-\mathrm{O}-\mathrm{P})$ \\
\hline & & & & & 805 & $\gamma(\mathrm{P}-\mathrm{O}-\mathrm{P})$ \\
\hline & & & & & $630,604,570$ & $\delta(\mathrm{O}-\mathrm{P}-\mathrm{O})$ \\
\hline
\end{tabular}

Полосы поглощения $v \mathrm{C}=\mathrm{O}$ амидных групп проявляются в виде интенсивных максимумов при $1670 \mathrm{~cm}^{-1}$, которые перекрываются с максимумом деформационного колебания $\delta \mathrm{NH}=1620 \mathrm{~cm}^{-1}$. Однако компоненты этого дуплета могут немного отличаться в спектрах композитного гидрогеля вследствие межмолекулярных взаимодействий. Наименее сильным, но тоже широким максимумом в интервале частот 1970-2400 см$^{-1}$ могли бы проявляться колебания связей О-Н в ионах.

Эффекты гидратации, т.е. образование водородных связей с участием адсорбированных молекул воды, также наблюдаются в колебательных спектрах. При этом имеется корреляция с полученными ранее результатами термогравиметрии и дифференциальной сканирующей калориметрии о распределении количества гидратированной воды и измененными физикохимическими параметрами в аморфных моно- и дифосфатов кальция и кальция-магния [6, 7], а также в гидрогелях на основе акриламида и акриловой кислоты [8].

Инкорпорирование в гидрогелевую матрицу акриловых сополимеров предварительно полученных аморфных моно- и дифосфатов кальция и кальция-магния отчетливо проявляется хорошо исследованными характеристическими колебательными частотами фосфат-ионов. Обычно монофосфатная группа $\mathrm{PO}_{4}{ }^{3-}$ проявляется несколькими дискретными компонентами.

В ИК-спектрах образцов, содержащих аморфных монофосфата кальция-магния, моно-дифосфата кальция и дифосфата кальция-магния, синтезированных в акриламидных гидрогелях, симметричное колебание $v(\mathrm{P}=\mathrm{O})=962 \mathrm{~cm}^{-1}$ проявляется слабым пиком. В спектре КРС ему соответствует интенсивный максимум в области $955 \mathrm{~cm}^{-1}[9]$.

Присутствие наноаморфного фосфата в составе гидрогелевого композита подтверждается интенсивным максимумом $v(\mathrm{P}-\mathrm{O})=960 \quad \mathrm{~cm}^{-1}$ в спектре КРС. Присутствие фосфат-ионов подтверждается появлением новой широкой интенсивной полосы поглощения с максимумами при 1060 и $990 \mathrm{~cm}^{-1}$. Самый низкочастотный из спектральных максимумов находится в области валентных колебаний связей $\mathrm{P}-\mathrm{O}$ в фосфатных анионах $\mathrm{PO}_{4}^{3-}$ и $\mathrm{P}_{2} \mathrm{O}_{7}^{4-}$

Полосы поглощения, относящиеся к колебаниям связей О-Н, для всех трех фосфатов почти одинаковы, профили наиболее низкочастотных линий имеют существенные различия. Причина этого заключается в разном вкладе поглощений $v \mathrm{PO}$, присущих моно- и дифосфату, так как одно из веществ содержит моно- и дифосфат, второе - только монофосфат, третье - монофосфат и пониженное по сравнению с первым веществом количество дифосфата. Однако из-за аморфности исходных соединений некоторые отдельные линии обычно сливаются в одну широкую асимметричную полосу.

\section{Литература}

1. Синяев В.А., Левченко Л.В., Батырбаева А.А. и др. Термические превращения аморфных фосфатов кальция, осажденных из водных растворов монофосфата и дифосфата // Известия МОН РК. Сер. хим. 2001. № 2. C. $104-108$.

2. Синяев В.А., Шустикова Е.С., Левченко Л.В. и др. Природа и поведение при нагревании осажденных фосфатов кальция-магния. // Журн. прикл. химии. 2003. Т.76. Вып. 9. С. 1415-1418.

3. Иманбеков К.И. Синтез и исследование аморфных органо-фосфатов кальция-магния на основе природных полимеров // Хим. журн. Казахстана. 2010. № 3. С.

4. Samchenko Yu, Ulberg Z., Pertsov N. Hydrogel medicinal systems of prolonged action // Progress in Colloid and Polymer Science. 1996. V.102. P. 118-122. 

1981.

5. Печковский В.В., Мельникова Р.Я. Атлас инфракрасных спектровфосфатов. Ортофосфаты. М.: Наука.

6. Sinyaev V.A., LeGeros R.Z., Levchenko L.V. State of water in amorphous calcium and calcium-magnesium phosphates Russian Journal of General Chemistry. 2008. V.78. P.864-867.

7. Синяев В.А., ЛеГерос Р.3., Левченко Л.В. Состояние воды в аморфных фосфатах кальция и кальциямагния // Журнал общей химии.- 2008. Т.78 (140). Вып.5. С.722-725.

8. Самченко Ю.М., Атаманенко И.Д., Полторацкая Т.П. Состояние воды в мелкодисперсных гидрогелях на основе акриламида и акриловой кислоты // Коллоид. журн. 2006. Т.68. № 5. С. 670-673.

9. Синяев В.А., Шустикова Е.С., Григгс Д. Состояние связей в Р-О в аморфных веществах, осажденных хлоридом кальция из водных растворов монофосфата в присутствии дифосфата и хлорида магния // Хим.журн. Казахстана. 2004. № 2. С. 9-18.

\title{
ИК-СПЕКТРОСКОПИЯ ӘДІСІМЕН АМОРФТЫ ФОСФАТТАР МЕН АКРИЛАМИД СОПОЛИМЕРЛЕРІ НЕГІЗІНДЕ ГИДРОГЕЛДІ КОМПОЗИТТЕРДІ ЗЕРТТЕУ
}

\author{
К.И. Иманбеков, Р.Г. Рысқалиева, К.М. Тамтиева, Г.И. Курбанова
}

Мақุалада композитті материалдар синтездеуде полиакриламидті гидрогелдер тесіктерінде түзілетін нано-аморфты фосфаттардың тербелмелі спектрлерінің өзгерісі құарастырылган. Гидрогелді құрылымва шовырланван кальиий, кальций-магний ортофосфаттарының аморфты фазалары микротесікті құрылымды болатындывы көрсетілген.

\section{RESEARCH OF HYDROGEL COMPOSITES BASED ON AMORPHOUS PHOSPHATES AND ACRYLAMIDE COPOLYMERS BY IR-SPECTROSCOPY}

\author{
K.I. Imanbekov, R.G. Ryskalyeva, K.M. Tamtiyeva, G.I. Kurbanova
}

The changes in vibrational spectrum of nano-amorphous phosphates, formed in the pores of polyacrylamide hydrogel structure under the synthesis of composite materials, are examined. It is shown that the amorphous phase of calcium orthophosphate, calcium - magnesium incorporated in the hydrogel structure, have a microporous structure.

\section{УДК 665.75:662.8}

\section{ПУТИ ЭФФЕКТИВНОГО ИСПОЛЬЗОВАНИЯ БУРОГО УГЛЯ МЕСТОРОЖДЕНИЯ КИЯКТЫ}

\author{
Ж.К. Каирбеков, Е.А. Аубакиров, *Н.Ж. Жалгасулы, Ж.Т. Ешова
}

НИИ новых химических технологии и материалов

*Институт горного дела им. Д.А. Кунаева, Алматы

В статье показана возможность эффективного применения мелких отсевов бурого угля месторождения «Кияктьл».

В условиях развития рыночной экономики и частного предпринимательства одним из важных и существенных факторов выживания предприятий, уменьшения риска и повышения их конкурентоспособности является использование всех возможностей в регионах и на местах для достижения этих целей.

К региональным возможностям и условиям развития производства товаров и услуг следует отнести природные (географические, климатические, гидрологические, наличие воды и других минеральных ресурсов), социальные (уровень развития транспортной, энергетической и другой инфраструктуры, наличие квалифицированной рабочей силы, состояние законодательства и нормативных актов для развития предпринимательства и т.д.), экономические (наличие инвестиций и возможность их рентабельного использования).

К местным условиям развития предпринимательства, возможно, отнести специфические особенности (преимущества и недостатки) всех природных, социальных и в том числе, экономических возможностей. 